\title{
La Trazabilidad del patrimonio arquitectónico del Estado
}

\author{
Alejandro Folga \\ FADU, Uruguay \\ alfotocopias@gmail.com \\ Leonardo Gómez Sena \\ FADU, Uruguay \\ leongs@adinet.com.uy
}

Traceability of architectural heritage of the State

\begin{abstract}
This paper describes the development of the agreement Traceability of public works, which consisted of the design and implementation of an information system on the management of the construction sites of the State, and performing digital graphics surveys of 30 buildings recognized presented patrimonial value. This project involved the formation of an interdisciplinary working group, composed of researchers from the Faculties of Architecture and Engineering.
\end{abstract}

Keywords: Traceability; Investigation; Interdisciplinary; Management; Heritage

\section{Introducción}

En esta ponencia ${ }^{1}$ se presenta una experiencia de investigación realizada a partir de un convenio interinstitucional, llevado a cabo entre la Facultad de Arquitectura $(F A R Q)^{2}$ de la Universidad de la República (UdelaR) y el Ministerio de Transportes y Obras Públicas (MTOP), cuyo objetivo fue el desarrollo de un Sistema de Información para la Trazabilidad de la Obra Pública. El convenio implicó el diseño e implementación de una base de datos sobre las obras edilicias en las que intervino el MTOP y la realización de relevamientos gráficos digitales de 30 edificios que pertenecen al Estado, de los cuales la mayoría son obras de reconocido valor patrimonial.

El concepto es una adaptación al español del término inglés traceability, que a su vez deriva de la palabra trace, que se traduce como 'rastro'. La Real Academia Española (RAE) ${ }^{3}$ nos propone dos diferentes definiciones que refieren al significado del concepto trazabilidad:

1. Posibilidad de identificar el origen y las diferentes etapas de un proceso de producción y distribución de bienes de consumo.

2. Reflejo documental de la trazabilidad de un producto.

Si la primera definición pone el acento en los procesos y los procedimientos técnicos, la segunda se refiere a sus resultados gráficos. Ambas cuestiones forman parte del proyecto que fue desarrollado. Si bien la trazabilidad está plenamente incorporada en las técnicas y procedimientos de la industria alimentaria, el concepto es adaptable a otros ámbitos en donde resulta valioso rastrear los procesos de producción de un determinado bien.
Aplicado al patrimonio arquitectónico y la gestión de las obras púbicas, el concepto de trazabilidad puede ser entendido como el conjunto de procedimientos y herramientas que permiten el conocimiento y el registro histórico de las intervenciones constructivas que se han realizado o se realizarán sobre los edificios. En concreto, mediante este concepto se busca una mayor eficiencia en la gestión patrimonial y un mejor aprovechamiento de los recursos inmuebles del Estado.

\section{Fundamentación y Antecedentes}

El desafío que este convenio proponía se presentaba como una oportunidad de aplicar y sistematizar una serie de procedimientos ensayados y enseñados por la academia, y de desarrollar así una investigación sobre el registro de información y el relevamiento de obras patrimoniales. En definitiva, el trabajo significó una oportunidad de aplicar los potenciales humanos generados en la formación universitaria y poner a prueba algunas investigaciones desarrolladas en la FARQ. De este modo también se cumplía con el objetivo de extensión al medio del conocimiento académico generado por la Universidad de la República.

\section{Investigación y extensión}

En el área de la extensión universitaria, la Universidad de la República establece como una de las competencias fundamentales el impulso de la divulgación cultural y científica en el seno de la sociedad. Su Ley Orgánica (1958) establece la necesidad de "difundir y defender la cultura, impulsar y proteger la investigación científica y las actividades artísticas y contribuir al estudio de los problemas de interés general y propender a su comprensión pública" (Ley No. 12.549, 1958). 
En el contexto cultural contemporáneo (signado por el papel del conocimiento y las comunicaciones) este objetivo adquiere nuevas connotaciones y proyecciones, ampliando y multiplicando los desafíos de la construcción de ese diálogo y de esa relación, de modo de hacer efectiva la contribución al desarrollo social y cultural integral de la comunidad.

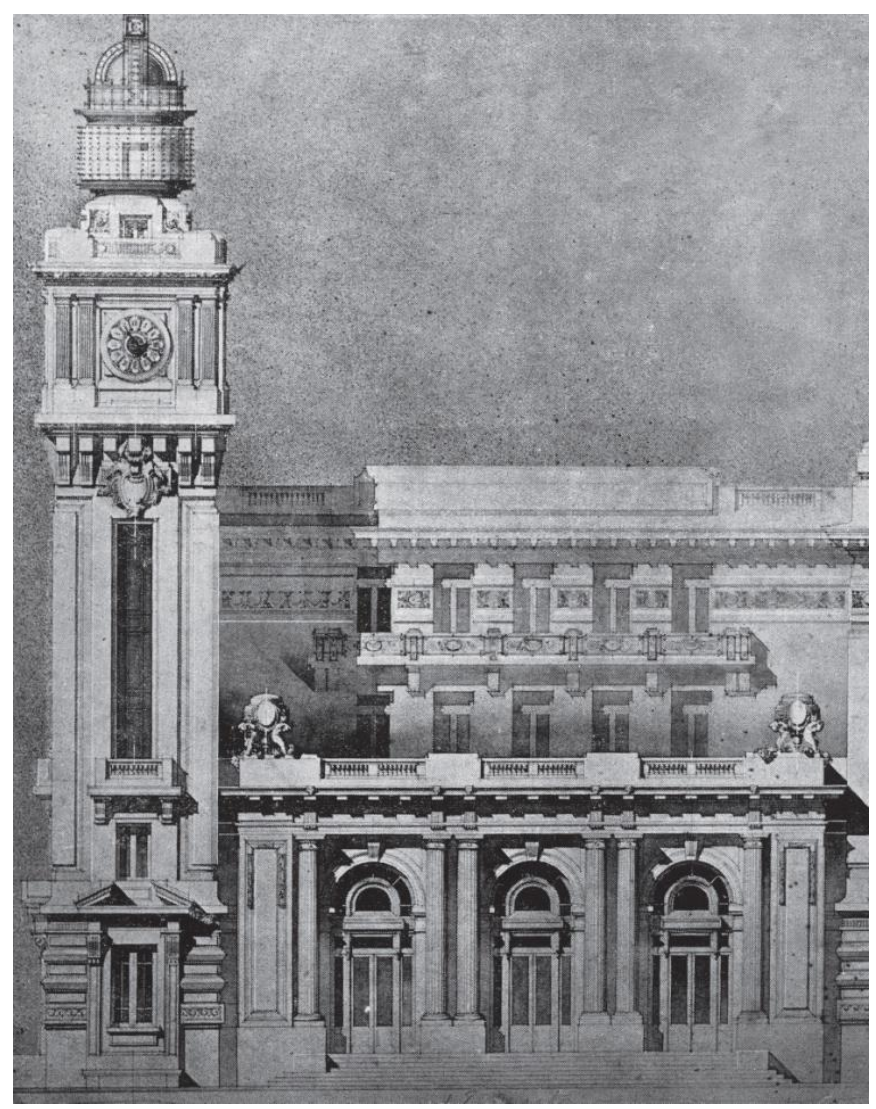

Figura 1: Fachada del proyecto para el Palacio de las Oficinas Públicas de Salto. Fuente: Revista Arquitectura № 62, Sociedad de Arquitectos del Uruguay, p. 193, Montevideo, Enero de 1923.

\section{Gestión patrimonial}

La importancia que ha adquirido la cuestión de la conservación y salvaguarda del patrimonio en el contexto cultural de los últimos años, ha ampliado sus alcances no solamente en términos físicos, temporales y temáticos, sino también en lo que refiere a aspectos conceptuales, debates teóricos y perspectivas de abordaje. Entre esas (relativamente) nuevas miradas, el campo de la gestión patrimonial ha adquirido una importancia creciente y un lugar propio, en tanto territorio específico de abordaje y preservación de bienes culturales.

Uno de los puntos de partida de la gestión integral del patrimonio, refiere al trascendente papel que le compete a la comunidad en la defensa de su herencia cultural. Ya sea en su propia comprensión, valoración y apropiación, así como en su involucramiento en los procesos de conservación y preservación. La confluencia de esta visión con los compromisos culturales asumidos por la Facultad en el marco de las políticas de extensión, se propone contribuir a la gestión patrimonial del patrimonio arquitectónico público de nuestro País, buscando aportar a su comprensión y difusión colectiva.

\section{Patrimonio arquitectónico del Estado}

Desde su fundación, en 1911, el MTOP ha sido el organismo estatal históricamente responsable del mayor volumen de construcción de obra pública en todo el territorio uruguayo. No obstante, en la actualidad el MTOP no ostenta el monopolio de la realización de las obras públicas, sino que comparte esa tarea con otras oficinas públicas que también se encargan del mantenimiento, el proyecto y la construcción de los edificios del Estado. Por este motivo la información sobre las obras y los edificios públicos no está centralizada, sino que se encuentra diseminada entre las diferentes oficinas de arquitectura de las administraciones estatales. Dentro de la órbita del MTOP la gestión técnica de las obras también se reparte entre diferentes secciones independientes, que están encargadas de realizar el proyecto, la dirección de obra o el contralor de las mismas. De modo que no existe un registro único, completo y centralizado de todas las actuaciones que el Ministerio realizó en su larga existencia.

La celebración de los cien años del MTOP, en 2011, se presentaba como una oportunidad histórica para actualizar el sistema de información sobre los edificios públicos. Con ese cometido la Dirección de Arquitectura (DNA) del MTOP recurrió a la Facultad de Arquitectura (FARQ) para desarrollar un proyecto de colaboración académicoinstitucional que culmina con la firma del convenio Trazabilidad de la Obra Pública4.

\section{Objetivos del proyecto}

El proyecto tuvo por objetivo general el desarrollo de una estrategia de relevamiento, registro y sistematización de la información sobre el "Edificio Público", en donde se abarquen los aspectos tecnológico-constructivos (un registro básico de lesiones y patologías existentes), los aspectos vinculados al funcionamiento (actividades actuales, usuarios, equipamiento, etc.), y el registro histórico de las distintas intervenciones que cada edificio ha sido objeto (trazabilidad de las obras).

Como uno de sus objetivos específicos se planteó la generación de una Base de Datos informática que contenga, organice y facilite el acceso a toda la información recabada sobre los edificios estudiados. Esta herramienta implicó un aporte significativo para la gestión de los edificios del Estado, sobre todo en lo que refiere a una mejor organización y uso de sus espacios, a una mayor eficacia en el empleo de los recursos públicos (gestión global, mantenimiento, costos energéticos, etc.), y en cuanto a políticas de mantenimiento preventivo y correctivo de los edificios.

Por otro lado, como segundo objetivo específico del proyecto, para poder realizar una evaluación técnica y proyectar futuras actuaciones sobre las obras (mantenimiento, reforma, conservación, etc.) es necesario contar con información gráfica completa, tanto desde el punto de vista físico-espacial como desde el técnicoconstructivo. Para ello se planteó la creación de un registro 
gráfico digitalizado, completo y actualizado del estado actual de cada uno de los edificios estudiados.

La existencia en el País de una larga tradición de nobles arquitecturas estatales y una política histórica de preservar edificios significativos mediante su incorporación al patrimonio público, ha estimulado que en la órbita del Estado resida un importante capital arquitectónico, que abarca desde la fundación del País hasta la contemporaneidad, incluyendo ejemplos de filiación neoclásica, ecléctica, modernista, así como obras vinculadas a las distintas vertientes de la arquitectura moderna. Por este motivo la generación de un sistema que permita su registro grafico y documentación se vuelve un aporte particularmente importante para las políticas y acciones vinculadas a su gestión patrimonial.

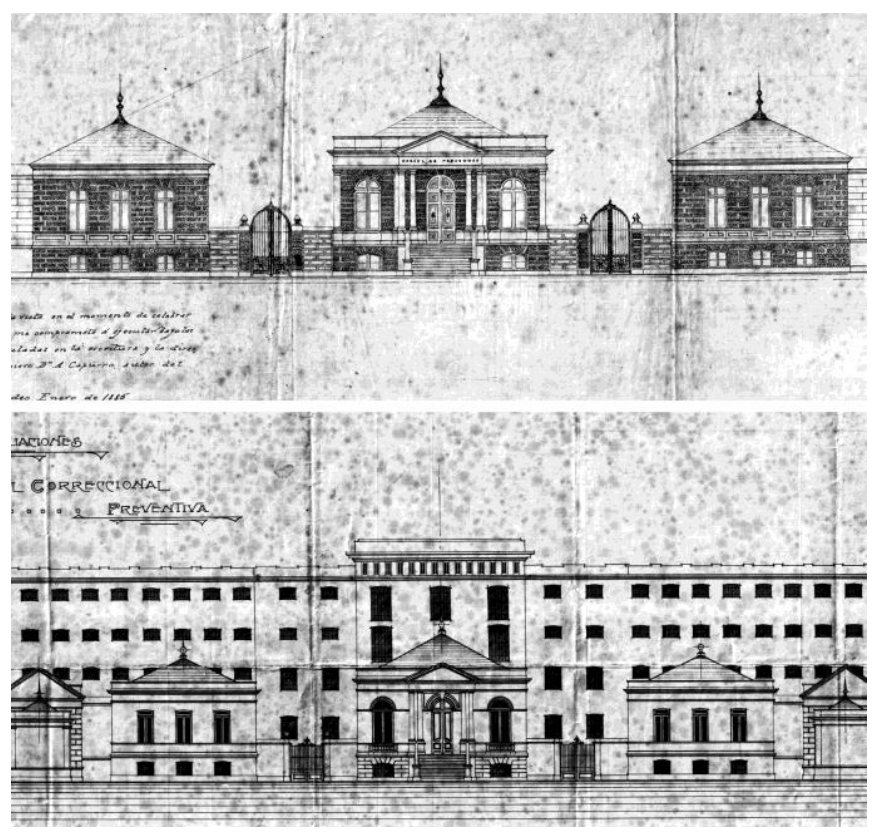

Figura 2: Planos originales del proyecto de la Cárcel de Miguelete, en Montevideo. Ninguna de las dos versiones diferentes de la Fachada se corresponde totalmente con el edificio finalmente construido. Fuente: Archivo documental del Departamento de Patrimonio Arquitectónico de la DNA/MTOP.

\section{Metodología}

Como forma de poner a prueba el modelo proyectado de registro de la información, durante los dos años que duró el convenio (2012 - 2014) se realizó el ingreso a la base de datos de un conjunto de 30 edificios que pertenecen al Estado. Estos ejemplos, además de ser edificios en los que la DNA haya actuado o le corresponda actuar, fueron seleccionados en función a su interés arquitectónico o su valor patrimonial.

\section{Sistema de información}

El registro propuesto para cada uno de los edificios seleccionados comprende desde aspectos generales relativos a su identificación, caracterización y divulgación pública; hasta datos particulares directamente vinculados a la gestión edilicia. Esto implicó: un análisis constructivo y arquitectónico-patrimonial, un registro de las intervenciones realizadas, un diagnóstico de su estado de conservación (que comprende un relevamiento de sus principales lesiones) y la generación de un archivo de gráficos, imágenes y documentos que integran el sistema de información materializado en la Base de Datos.

La recopilación y organización de estas informaciones, requirió un trabajo de investigación en archivos, de búsqueda de antecedentes sobre las etapas de construcción y de las alteraciones u operaciones de conservación y recuperación realizadas, así como también de los proyectos aún no realizados.

Para llevar a cabo estas tareas se conformó un equipo interdisciplinar integrado por docentes e investigadores de las tres diferentes áreas de la $\mathrm{FARQ}^{5}$. El área teórica-crítica, representada por investigadores del Instituto de Historia (IHA), estuvo encargada de la realización de estudios sobre algunos edificios relevados. El área tecnológica, representada por un equipo docente especializado perteneciente al Instituto de la Construcción (IC), tuvo la responsabilidad de definir las propiedades relativas a los criterios constructivos y de diagnóstico del estado de conservación de las obras (registro de las características estructurales y constructivas, terminaciones, aberturas, seguridad, instalaciones y relevamiento de lesiones). El área de proyecto y representación, representada en el equipo de coordinación, se encargó de coordinar y llevar a cabo el relevamiento gráfico y fotográfico de las obras estudiadas. Por último, para el desarrollo del diseño informático y la implementación de la base de datos, se contó con la colaboración de investigadores del Instituto de Computación de la Facultad de Ingeniería (INCO-FING) ${ }^{6}$.

\section{Investigación y Enseñanza}

Para la Facultad de Arquitectura los proyectos de investigación a menudo constituyen oportunidades para poder realizar, en forma paralela, actividades de enseñanza. En ese sentido el proyecto desarrollado buscó aprovechar la realización del Convenio entre el MTOP y la FARQ para llevar a cabo el ensayo de experiencias de investigación y enseñanza que de otro modo quedarían confinadas en el ámbito de la academia. En particular, para las tareas del relevamiento gráfico de los planos de los 30 edificios seleccionados (y como apoyo del numeroso equipo de investigación antes mencionado) se conformó un equipo integrado por estudiantes avanzados de arquitectura ${ }^{7}$ que trabajaron en régimen de pasantía bajo la dirección de los docentes coordinadores del proyecto.

La Facultad de Arquitectura (FARQ) posee un sistema de pasantías mediante el cual estudiantes avanzados pueden acceder a experiencias laborales en diferentes oficinas de arquitectura de la administración pública. Estas pasantías son reconocidas por la FARQ como una instancia formativa y pueden ser revalidadas como una actividad formal de aprendizaje, equiparándose a asignaturas optativas. De modo que estas actividades otorgan créditos académicos en la carrera de Arquitectura. 
La adopción de este sistema implicó que en lugar de utilizar a los pasantes como simple "mano de obra" el trabajo desarrollado se constituyera en una instancia educativa, en una experiencia extracurricular de formación como futuros profesionales. En ese sentido, el desarrollo de la experiencia se basó en otros proyectos de investigación previamente llevados a cabo con estudiantes de grado de los cursos curriculares de la FARQ.

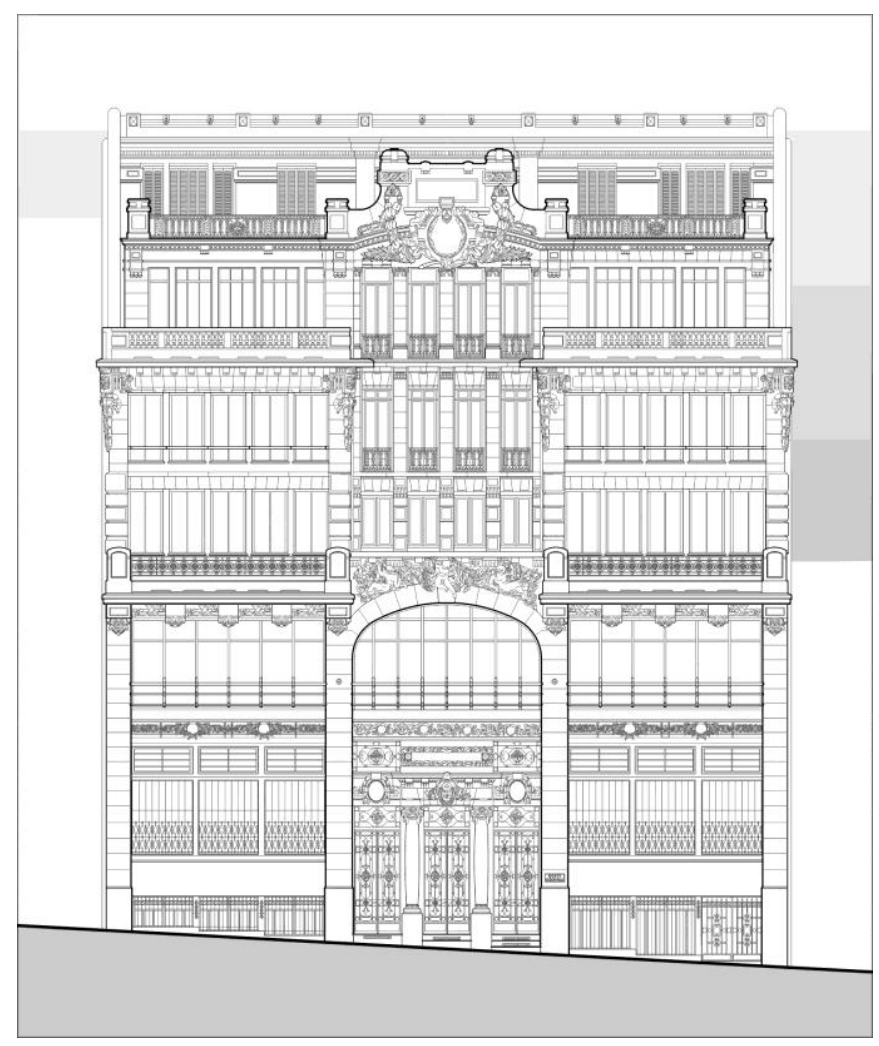

Figura 3: Fachada de la Corte Electoral de Montevideo. Dibujo digital realizado a partir del relevamiento fotográfico y posteriormente "calcado" en CAD. Realización: equipo de trabajo de Trazabilidad de la Obra Pública, año 2013.

\section{Desarrollo del registro gráfico}

Para realizar el registro gráfico de los edificios seleccionados el equipo de coordinación desarrolló un sistema de trabajo que se implementó desde el comienzo del proyecto. Este sistema implicó una serie de etapas que culminan con la realización, por parte del equipo de pasantes, de los gráficos digitales de todos los edificios estudiados. En líneas generales, el procedimiento constó de las siguientes etapas:

\section{a / Organización de la información gráfica existente}

Dado que en la mayoría de los casos no existen gráficos digitales, la primera tarea consistió en la investigación de los antecedentes gráficos existentes en los archivos del MTOP. Para la generación de un Archivo Gráfico de cada edificio se partió del escaneo de los planos en papel, y se realizó un asesoramiento a los técnicos del MTOP y un seguimiento de las tareas de selección, ordenamiento, preservación y digitalización de dicha información.

\section{b / Relevamiento de los edificios}

Dado que, por lo general, los antecedentes gráficos que el MTOP posee no están actualizados o son incompletos, a partir del estudio de los antecedentes se coordinaron visitas a los edificios, para realizar un exhaustivo trabajo de campo, que incluyó un relevamiento dimensional "in situ" y un registro fotográfico completo.

\section{c / Digitalización en formato CAD}

Partiendo de los antecedentes gráficos existentes y de la información obtenida en el trabajo de campo, posteriormente se realizó la digitalización de los planos en formato CAD. Para esto se optó por generar dibujos en el Sistema Diédrico Ortogonal (plantas, fachadas y cortes), conformando así una serie de gráficos individuales de cada inmueble que permiten una descripción muy completa de las características arquitectónicas.

\section{d / Normalización del dibujo}

Como parte del proceso de registro de la información, se definió y adoptó un protocolo de trabajo que estableciera criterios muy precisos para el dibujo en CAD. De manera que en todos los dibujos se aplican los mismos criterios en la organización de la información, independientemente de los diferentes dibujantes que se ocupan de realizar el trabajo.

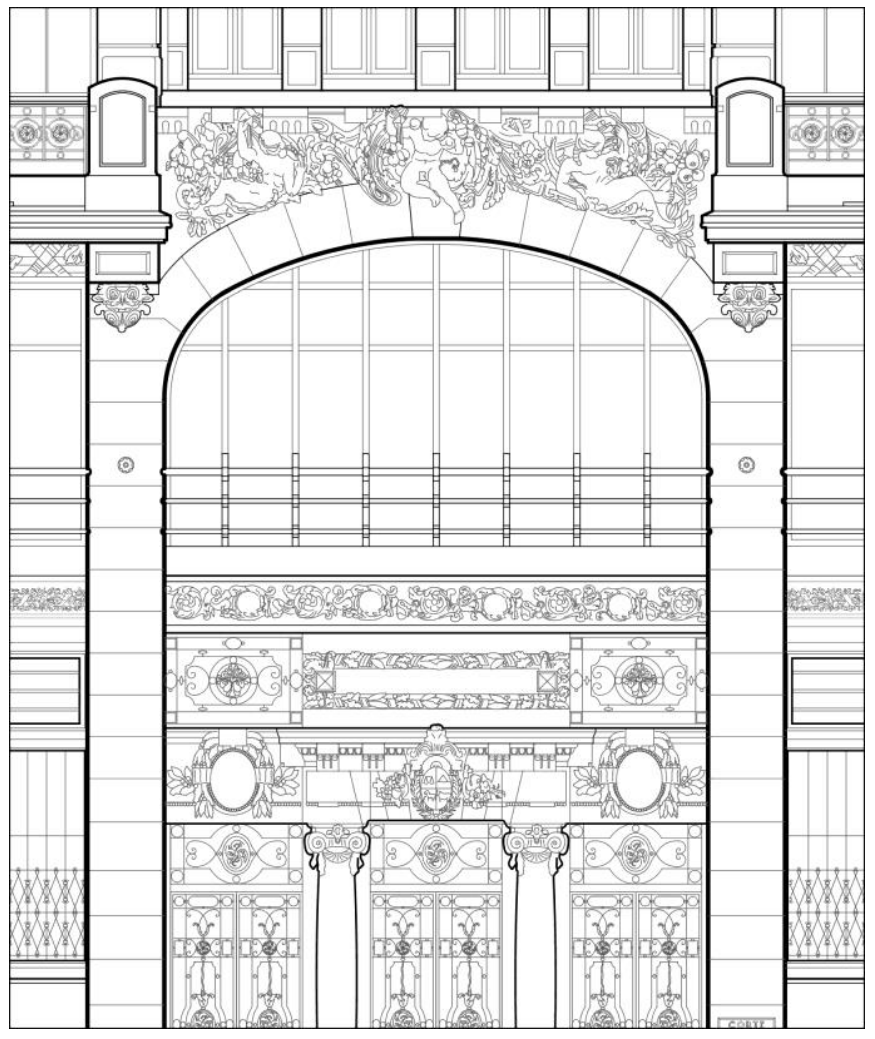

Figura 4: Detalle de la fachada de la Corte Electoral de Montevideo. Realización: equipo de trabajo de Trazabilidad de la Obra Pública, año 2013.

\section{e / Criterios gráficos}

Por el tipo de edificios que fueron relevados (predominantemente arquitectura de estilo historicista, con gran profusión de detalles decorativos y ornamentación 
añadida) se optó por un registro completo, detallado y exhaustivo de las obras. Esto implicó la realización de dibujos que incluyesen un alto grado de definición de los detalles correspondientes a la materialidad (juntas, uniones, aparejos, texturas, etc.), 0 de elementos ornamentales (detalles de carpinterías, herrerías, vitrales, estatuaria añadida, etc.).

Como resultado final de este proceso se obtienen unos geometrales muy detallados y rigurosos, que representan con alto grado de fidelidad la forma, el espacio y las características estilísticas de las arquitecturas relevadas. De esta manera los dibujos superan el mero uso instrumental con que fueron planteados al inicio del proyecto, y se convierten en un documento gráfico de alto contenido simbólico y figurativo. Este carácter hace que los gráficos se constituyan en un instrumento de gran atractivo visual que permite ser utilizado con el objetivo de divulgación pública de las obras arquitectónicas patrimoniales.

\section{Divulgación pública}

Además de atender a los aspectos vinculados a las prácticas de gestión en la órbita del Estado, el Sistema busca constituirse en un espacio de referencia en lo que refiere a la divulgación cultural del valioso patrimonio arquitectónico público con que cuenta el País. Por esta razón se previó una interface de acceso totalmente público, a la que es posible acceder para conocer información general de cada uno de esos edificios, su historia, sus imágenes, sus antecedentes y otros aspectos de interés colectivo.

En esa misma lógica fue concebida la realización del libro Trazabilidad de la Obra Pública (publicado en 2014), producto que recoge los principales resultados del trabajo realizado por la Facultad de Arquitectura. El libro tiene por objetivos dar difusión a la herramienta que supone el Sistema de Información para la Trazabilidad de la Obra Pública y, a la vez, establecer un registro de la actividad académica (investigación, enseñanza y extensión) que supuso la realización del convenio.

En el libro se explicitan los objetivos generales del convenio, se explica el concepto de Trazabilidad aplicado al patrimonio edilicio del Estado, se define la metodología de trabajo utilizada para el relevamiento gráfico de las obras, y se desarrollan los criterios de diseño del Sistema de Información empleado en la base de datos generada. Además se realiza un análisis de once obras arquitectónicas (de gran relevancia para la arquitectura nacional) que fueron tomadas como ejemplo de aplicación de la herramienta de la trazabilidad. De esta manera se busca promover la valoración de obras arquitectónicamente destacadas, pero que no han sido suficientemente documentadas y estudiadas por la historiografía.

De forma consistente con los cometidos enunciados, la redacción, el diseño y la coordinación editorial del libro fueron realizados por el equipo de docentes de la FARQ que participaron del convenio. El equipo incluyó a docentes del área de proyecto y representación, del área tecnológica y del área teórico-crítica. Los abordajes histórico-críticos fueron realizados por investigadores del Instituto de Historia de la
FARQ y las fotografías fueron realizadas por fotógrafos del Servicio de Medios Audiovisuales de la FARQ.

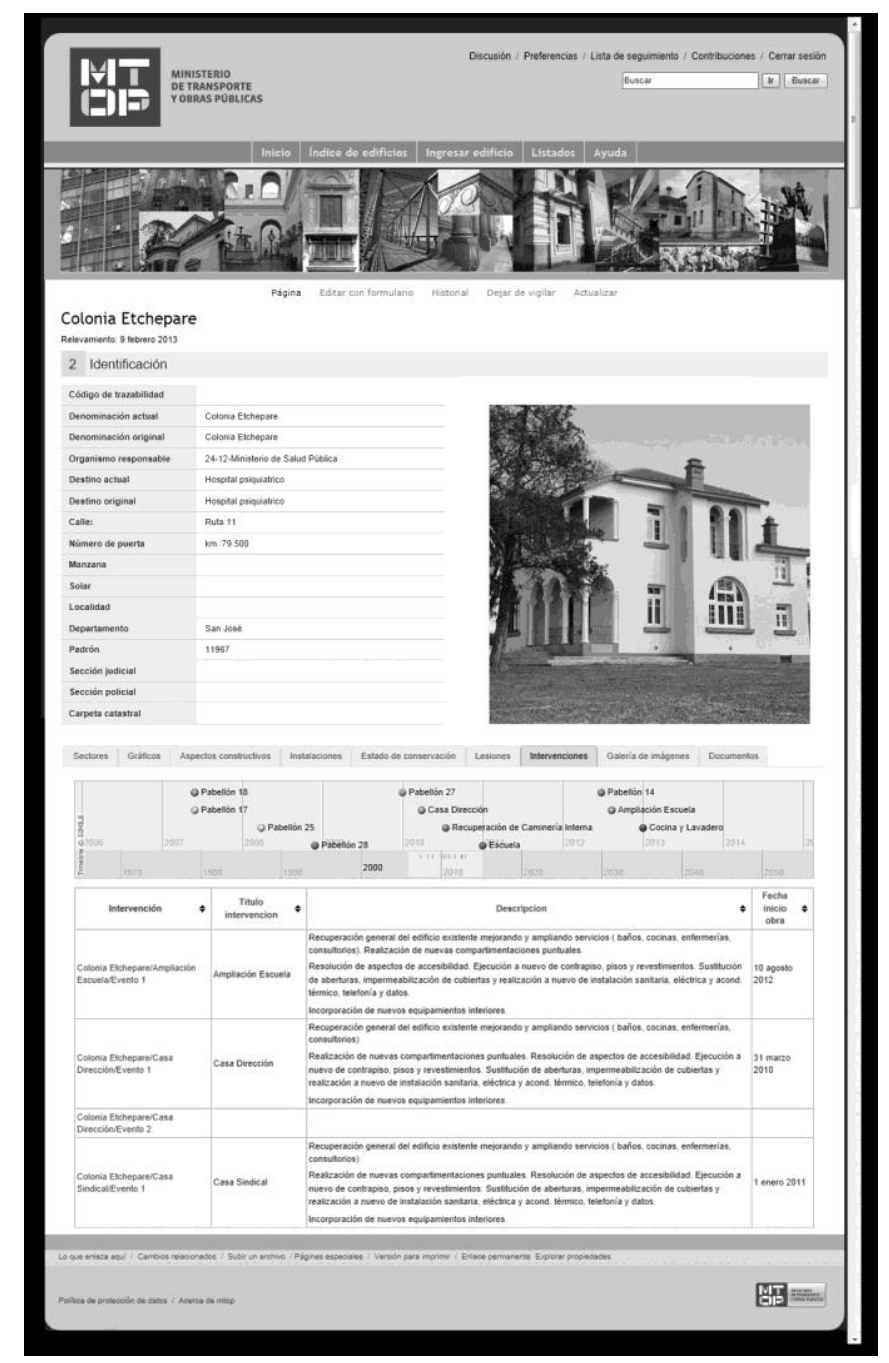

Figura 5: Visualización de la Página Trazabilidad de la Obra Pública. Sitio Web del Ministerio de Transporte y Obras Públicas.

\section{Resultados y Conclusiones}

El principal resultado del convenio, realizado a lo largo de dos años, permitió implementar una primera versión de la base de datos y ensayar el funcionamiento de la misma como herramienta de gestión para los técnicos del MTOP. Como segundo resultado, permitió generar y perfeccionar una metodología de trabajo para el relevamiento gráfico digital de ejemplos de arquitectura. Por último, la publicación del libro Trazabilidad de la Obra Pública permitió establecer un registro de los resultados obtenidos y dar difusión pública al trabajo académico realizado por la FARQ en el marco del convenio.

El cumplimiento de esta primera etapa permitió ensayar el funcionamiento de la Base de Datos y posibilitó la implementación y generalización de la misma como una herramienta de trabajo para los técnicos del MTOP. Como 
paso siguiente, luego de una etapa de revisión y puesta a punto del diseño, se prosiguió con una ampliación del universo de los edificios a ser ingresados. Si consideramos que el Estado tiene repartidos entre las diferentes administraciones unos 12.500 edificios, y que más de la mitad no está debidamente registrado, el universo de trabajo es muy vasto y aún resta una enorme tarea por hacer.

Considerando que el MTOP es el organismo público encargado de gestionar el mayor volumen de obra construida en todo el territorio nacional, la implementación del Sistema de Información implica un aporte significativo para la gestión de los edificios del Estado. En primer lugar, en cuanto a políticas de mantenimiento preventivo y correctivo de los edificios; en segundo lugar, para su mayor y mejor difusión pública.

Por otro lado, el trabajo desarrollado con los pasantes constituyó una experiencia de investigación y enseñanza sobre los procedimientos de relevamiento edilicio, y permitió poner en práctica una serie de criterios, estrategias y técnicas gráficas de representación de arquitectura. En definitiva, uno de los principales resultados de la investigación realizada consiste en la generación de una metodología de trabajo para realizar el registro de ejemplos de arquitectura de valor patrimonial.

En este momento (setiembre de 2016) ante la posible ampliación del Convenio original, se abren para la FADU nuevas oportunidades de trabajo con el MTOP, en las que se espera poder profundizar y ampliar la investigación realizada durante la primera etapa.

\section{Notas}

${ }^{1}$ Este texto tiene como antecedentes la ponencia: El registro del patrimonio arquitectónico del Estado, presentada al Congreso: VIII Encuentro Internacional Ciudad Imagen y Memoria, realizado en Cuba, en Mayo de 2013. En segundo lugar, el artículo "El registro gráfico de las arquitecturas patrimoniales", autor: Alejandro Folga y "Trazabilidad de la obra Pública", autor: Leonardo Gómez. Ambos publicados en el libro Trazabilidad de la obra pública, AAVV, Montevideo, 2014.

2 El nombre de la Facultad de Arquitectura (FARQ) cambió por Facultad de Arquitectura, Diseño y Urbanismo (FADU) en 2015. En este trabajo utilizaremos la nomenclatura vigente al momento de realizar el Convenio.

${ }^{3}$ Diccionario consultado en línea: http://www.rae.es/

4 El proyecto fue realizado por el equipo de coordinación integrado por el Arq. Leonardo Gómez y el Arq. Alejandro Folga. En el proceso de negociación del convenio participó directamente el Decano, Dr. Arq. Gustavo Scheps y el Asistente Académico Arq. Luis Oreggioni, que fue el encargado de coordinar la gestión entre el MTOP y la FARQ.

5 El grupo de trabajo de la Facultad de Arquitectura se compuso de la siguiente manera: el área teórico-crítica estuvo representada por docentes e investigadores del Instituto de Historia (IHA), que fueron encargados de la realización de estudios histórico-crítico de algunos edificios relevados. El equipo estuvo integrado por los Profesores Adjuntos: Arq. Pedro Livni, Arq. Mauricio García, Arq. Mery Méndez; y por los Ayudantes: Arq. Rogelio Texeira, Arq. Magdalena Peña, Arq. Miriam Hojman, Bach. Tatiana Rimbaud. Del área tecnológica participaron las investigadoras Arq. Giannella Mussio y Arq. Carola Romay. Por último, el Servicio de Medios Audiovisuales (SMA) participó realizando reportajes fotográficos de las obras seleccionadas, las fotografías fueron realizadas por: Arq. Alberto Marcoveccio, Arq. Julio Pereyra y Arq. Danaé Teresa Latchinian. El equipo de coordinación del proyecto estuvo formado por el Arq. Alejandro Folga (área de proyecto y representación) y Arq. Leonardo Gómez (área teórico-crítica).

${ }^{6}$ El equipo de investigadores del INCO estuvo integrado por: Ing. Fernando Carpani, Ing. Benjamín Machín, Ing. Mónica Martínez.

7 El equipo de Pasantes estuvo integrado por los siguientes estudiantes de arquitectura: Noelia Bado, Verónica Cabrera, Natalia Collares, Facundo García, Fernanda Rodríguez, Alejandra Serra y Victoria Tellería.

\section{Referencias}

Carpani, F. y Gómez, L. (2014). "Sistema de Información de Trazabilidad de la Obra Pública". En Trazabilidad de la obra pública (29-38). Montevideo: Farq.

Folga, A. (2014). "El registro gráfico de las arquitecturas patrimoniales". En Trazabilidad de la obra pública (36-43). Montevideo: Farq.

Folga, A., Gómez, L. (2013) El registro del patrimonio arquitectónico del Estado, En Libro de actas del VIII Encuentro Internacional Ciudad Imagen y Memoria, Santiago de Cuba, Cuba.

Gómez, L. (2014) "Trazabilidad de la obra Pública" En Trazabilidad de la obra pública (24-25). Montevideo: Farq.

Ley № 12.549 Ley Orgánica de la Universidad de la República (1958). Diario Oficial, Montevideo, Uruguay, 29 de octubre de 1958.

Sociedad de Arquitectos del Uruguay (Enero de 1923). Revista Arquitectura (62), p. 193. 